\title{
KAJIAN EKONOMI PENGGUNAAN ADDITIVE PADA PAKAN IKAN DALAM USAHA PEMBESARAN IKAN MAS
}

\author{
Oleh : \\ Asep Ahmad Subagio \\ Dosen Jurusan Penyuluhan Perikanan Sekolah Tinggi Perikanan
}

\begin{abstract}
ABSTRAK
Pelaksaaan kajian ekonomi penggunaan makanan addittive dalam usaha pembesaran ikan mas dilakukan di Waduk Cirata, Cianjur dari bulan Juni sampai dengan Agustus 2009. Kajian ini bertujuan untuk menhitung kelayakan usaha pembesaran ikan mas setelah mengalami perubahan teknologi dengan menambah additive pada makanan pelet yang diberikan pada ikan yang dipelihara dalam kantong jaring apung.

Pengakajian ini dilakukan menggunakan rancangan kajian sederhana. Perlakuan yang dilaksanakan pada pengakjian ini adalah menambah makanan additive pada pakan/pelet. Dosis additive yang ditambahkan yaitu $5 \mathrm{cc} / \mathrm{kg}$ pelet. Selama pengkajian dilakukan sampling sebanyak 5 kali dengan penggunaan sample sebanyak $5 \mathrm{~kg}$, dimana setiap kilogramnya dihitung jumlah biomasanya dan ditimbang berta per ekornya. Sampling dilakukan untuk mengetahui laju pertumbuhan ikan yang selanjutnya dihubungkan dengan tingkat efesiensi pakan yang terserap oleh ikan.

Analisa ekonomi yang dilakukan meliputiR/C ratio dan $\mathrm{B} / \mathrm{C}$ ratio yaitu untuk mengetahui kelayakan usaha pembesaran ikan mas dalam KJA dengan perubahan teknologi berupa penambahan additive pada makanan. Selama pengkajian diukur laju pertumbuhan ikan dengan hasil menunjukan bahwa ikan-ikan yang mendapat perlakuan penambahan additive mengalami pertumbuhan yang lebih cepat dengan perbedaan angka laju pertumbuhan mencapai rata-rata sebesar 53 gram. Selanjutnya dari sisi analisa $\mathrm{R} / \mathrm{C}$ ratio dan $\mathrm{B} / \mathrm{C}$ ratio menunjukan angka yang lebih baik yaitu 1,3 dan 5,3 yang berarti bahwa perubahan teknologi penggunaan additive layak dijadikan sebagai metoda budidaya pembesaran ikan mas yang layak untuk usaha.
\end{abstract}

Kata kunci : KJA, Additive, Ikan Mas (Cyprinus carpio)

\section{PENDAHULUAN}

\section{Latar belakang}

Luas perairan umum Indonesia lebih dari 50 juta ha, terdiri dari perairan rawa 39,4 juta ha, perairan sungai beserta lebarnya 11,95 ha, serta danau alam dan danau buatan (waduk) tercatat seluas 2, juta ha ( Rochdianto, 1986). Waduk ádalah salah satu sumberdaya perairan umum yang memiliki potensi besar diberbagai aspek kehidupan. Menurut Teguh (198) Waduk biasanya dibangun untuk beberapa tujuan, seperti pembangkit listrik tengaga air, irigási atau pengendali air. Selain kegunaan tersebut waduk juga dimanfaat sebagai wahan wisata air, konservasi hewan air dan sebagai tempat untuk usaha terutama usaha budidaya ikan. 
Waduk Cirata merupakan salah satu waduk yang ada di Jawa Barat. Waduk Cirata terbentuk dari adanya genangan air seluas 66.003.466 $\mathrm{m}^{2}$ akibat pembangunan waduk yang membendung Sungai Citarum, genangan waduk tersebut tersebar di 3 Kabupaten, yaitu Kabupaten Cianjur, Bandung dan Purwakarta. Genangan air terluas berada di Kabupaten Cianjur dengan luas 29.603.299 m.

Budidaya ikan dalam keramba jaring apung (KJA) di tiga waduk di Jawa Barat berkembang pesat. Pada tahun 1999 sudah mencapai 21.872 unit di waduk Saguling dan Cirata serta 2.194 unit ( 1998 ) (Krismono \& Wahyudi, 2001).

Tempat budidaya ikan antara lain berupa kantong jaring terapung (Kamiso, 2000). Menurut Zulkifi (1996) kanton jaring apung harus dalam bentuk sempurna agar ruang untuk ikan yang tersedia sesuai dengan ukuran kantong. Hampir semua jenis ikan dapat dipelihara dalam kantong jaring apung (Zulkifli, 1996). Ikan mas (Cyprinus carpio) merupakan salah sat jenis ikan yang bernilai ekonomis. Ikan ini telah memasyarakat dan menduduki terbesar unutk jenis ikan budidayaair tawar di Indonesia.

Banyak faktor yang mempengaruhi keberhasilan usaha pembesaran ikan termasuk pada usaha pembesaran ikan mas dalam kantong jaring apung. Salah faktor yang cukup berpengaruh adalah harga pakan yang cenderung terus meningkat tanpa diimbangi dengan kenaikan harga ikan itu sendiri. Faktor laninnya adalah komoditi ikan hasil tangkapan dari laut biasanya pada saat musin angin timur dengan produksi yang berlimpah sangat mempengaruhi terhadap nilai jual ikan mas.

Ketidak seimbangan antar biaya produksi usaha pembesaran ikan mas dengan harga jual ikan mas mengakibatkan terjadinya kerugian dalam perhitungan/analisa usahanya, sehingga utnuk mengantisipasinya perlu adanya jalan keluar. Penambahan makanan additive sebagai upaya perubahan teknologi diharapkan dapat menjadi solusi untuk mengatasi terjadinya kerugian usaha yang diakibatkan oleh ketidak seimbangan faktor usaha tersebut.

\section{Rumusan Masalah}

Kawasan waduk cirata memiliki luas $71.112 .824 \mathrm{~m}^{2}$ terdiri dari $5.081 .358 \mathrm{~m}^{2}$ wilayah daratan dan $66.031 .466 \mathrm{~m}^{2}$ wilayah perairan. Fungsi utama waduk adalah sebagai pembangkit tenaga listrik, selain itu terdapar fungsi lain seperti irigasi pertanian, pengendalian banjir, perikanan konservasi air, dan pariwisata.

Pembangunan dan pengeloaan Waduk Cirata akan menghasilkan nilai manfaat yang besar terutama kegiatan perikanan, dalam hal ini pemerintah memberdayakan dan memanfaatkan keberadaan waduk untuk kepentingan masyarakat agar dapat meningkatkan perekonomian dan kesejahteraan. Kegiatan usaha perikanan yang dilakukan di Waduk Cirata adalah kegiatan usaha budidaya ikan dalam kantong jaring apung.

Adanya ketidakseimbangan faktorfaktor usaha antara input dan ouput yang menyebabkan terjadinya kerugian dalam usaha pembesaran ikan mas dalam kantong jaring apung, diharapkan dapat diatasi melalui perubahan teknologi berupa penambahan makanan additive. 


\section{Tujuan penelitian}

Penelitian ini bertujuan untuk

menghitung kelayakan usaha pembesaran ikan mas setelah mengalami perubahan teknologi dengan menambah makanan additive dalam keramba jaring apung di Waduk Cirata Cianjur Provinsi Jawa Barat.

\section{MEODE PENELITIAN}

\section{Waktu dan Tempat}

Penelitian ini akan dilakukan di Waduk Cirata Kabupaten Cianjur Provinsi Jawa Barat. Pada bulan Juni - Agustus 2009.

\section{Alat dan Bahan}

Penelitian ini menggunakan alat dan bahan sebagai berikut :

1. Alat - alat :

- Wadah budidaya berupa jaring kantong

- Aat-alat perikanan

- Timbangan

2. Bahan-bahan :

- Benih ikan mas

- Pelet

- Additive "GH"

\section{Perlakuan}

Penelitian ini mengunakan rancangan kajian sederhana menggunakan satu faktor dan satu ulangan.

Perlakuan yang dilaksanakan pada penelitian ini adalah menambah additive "GH" pada pakan/pelet. Jumlah additive yang ditambahkan mengikuti petunjuk penggunanaan additve "GH" yaitu dengan dosis $5 \mathrm{cc} / \mathrm{kg}$ pelet. Pelaksanaan Penelitian

Sebelum penelitian dimulai, terhadap peralatan perlengkapan dilakukan pengecekan agar benar-benar siap digunakan. Pada awal penelitian dimulai penimbangan berat dan perhitungan jumlah ikan untuk mengetahui berat biomasa, dan jumlah biomasa per satu kilogram.

Kedalam setiap kantong jaring/wadah budidayaditebar benih ikan mas seberat $35 \mathrm{Kg}$. Selama pemeliharaan ikan diberi pakan dengan dosis $3-10 \%$ dari berat biomasa dengan kenaikan dosis secara bertahap berdasarkan pertumbuhan ikan dimulai dengan dosis $3 \%$ dan diakhiri dengan $10 \%$.

\section{Pengamatan}

Selama penelitian samping sebanyak 5 kali samping dengan pengambilan sample sebanyak $3 \mathrm{Kg}$, setiap kilogramnya dihitung jumlah biomasanya dan ditimbang berat per ekornya.

\section{Analisis Ekonomi Usaha KJA}

Analisis ekonomi dilakukan untuk mengetahui apakah kegiatan usaha KJA di Waduk Cirata menguntungkan atau layak diusahakan dari segi finansialnya.

\section{Revenue-Cost ratio (R/C)}

Perbandingan antara penerimaan dan pengeluaran biaya. Bila R/C lebih dari satu dianggap layak, R/C kurang satu dianggap tidak layak, $\mathrm{R} / \mathrm{C}=$ satu (Trade Off) dapat dilaksanakan atau tidak tergantung keputusan dari pihak yang akan melaksanakan usaha.

\section{Break Event Point (BEP)}

Merupakan suatu alata ukr untuk mengetahui tingkat peluang pokok dimana usaha berada pad titik nol yaitu tidak dalam keadaan rugi dan tidak dalam keadaan untung. 
Penentuan BEP biasa dilakukan dalam bentuk unit atau rupiah dengan rumus sebagai

berikut :

BEP (Unit) : _Total biaya tetap

Harga jual - Biaya Variable pe unit

BEP (Rupiah) :_Total biaya tetap

\section{1 - Biaya Variable per unit Harga jual}

\section{Bnefit - Cost ratio $(\mathrm{B} / \mathrm{C})$}

Perbandingan antara semua Present Value (PU) yang bernilai positif dengan Present Value (PU) yang bernilai Negatif dari suatu periode proyek tertentu.

Suatu investasi dikatak layak jika B/C lebih besar dari 1, dan tidak layak jika B/C lebih kecil dari 1 , sedangkan bila $\mathrm{B} / \mathrm{C}$ sama dengan 1 keputusan investasi tergantung pada keputusan pemilik modal/ pemlik usaha.

$\mathrm{B} / \mathrm{C}$ ratio juga digunakan unutk menaikan tingkat kelayakan atas perubahan teknologi yang mengakibatkan adanya perubahan volume pada struktur biaya.

$$
\frac{\text { Output Baru }- \text { Output Lama }}{\text { Input Baru }- \text { Input Lama }=}<1 \text { : }
$$

\section{HASIL DAN PEMBAHASAN}

Pengaruh penggunaan additive $\mathrm{GH}$ secara teknis dilihat dari dua sisi pengukuran yang mengarah kepada laja pertumbuhan yaitu dari sisi perkembangan pertumbuhan terhadap jumlah ekor ikan dalam setiap kilogram ikan mas (Cypinus Carpio) selama kegiatan berlangsung disajikan dalam tabel 1 .

Tabel 1. Laju Pertumbuhan Ikan Mas Dilihat Dari Jumlah Ekor Per Kilogram Ikan

\begin{tabular}{|l|c|c|c|c|c|}
\hline $\begin{array}{l}\text { Perlakuan pada } \\
\text { pakan }\end{array}$ & $\begin{array}{c}\text { O } \\
(\mathrm{Gr})\end{array}$ & $\begin{array}{c}\text { I } \\
(\mathrm{Gr})\end{array}$ & $\begin{array}{c}\text { II } \\
(\mathrm{Gr})\end{array}$ & $\begin{array}{c}\text { III } \\
(\mathrm{Gr})\end{array}$ & Panen \\
\hline Non Additive & 18 & 18 & 36 & 87 & 227 \\
Plus Additive & 18 & 23 & 52 & 101 & 280 \\
\hline Selisih & 0 & 5 & 16 & 14 & 53 \\
\hline
\end{tabular}

Laju pertumbuhan yang baik ditunjukan dengan makin beratnya bobot rata-rata dalma setiap ekor ikan, semakin berat bobot ikan menunjukan bahwa pertumbuhan semakin baik. Berdasarkan tampilan data pada table 1 di atas, memperlihatkan bahwa penggunaan Additive mempunyai pengaruh yang baik, dimana angka-angka hasil penimbangan ratarata pada setiap ekor ikan menunjukan ke arah yang lebih besar yang berarti menunjukan perubahan yang lebih baik.

Dari tabel 1 diatas dapat dilihat sejak penebaran (O) hingga sampling III menunjukan perubahan angka bobot per ekor ikan pada ikan yang diberi pakan dengan penambahan makanan additive lebih besar atau lebih berat dibandingkan dengan ikan yang diberi pakan tanpa penambahan makanan additive. Pada saat penebaran $(\mathrm{O})$ berat ikan 
rata-rata setiap ekor 18 gram, selanjutnya pada setiap sampling angka penambahan berat bobot ikan yang diberi additive $\mathrm{GH}$ selalu lebih berat dengan selisih berat pada setiap sampling seberat 5 gr pada sampling I, $16 \mathrm{gr}$ pada sampling II, 14 gr pada sampling III dan 53 pada saat panen

Grafik daya pertumbuhan ikan mas berdasarkan jumlah ekor perkilogrm bobot ikan dapat dilihat pada gambar 1 .

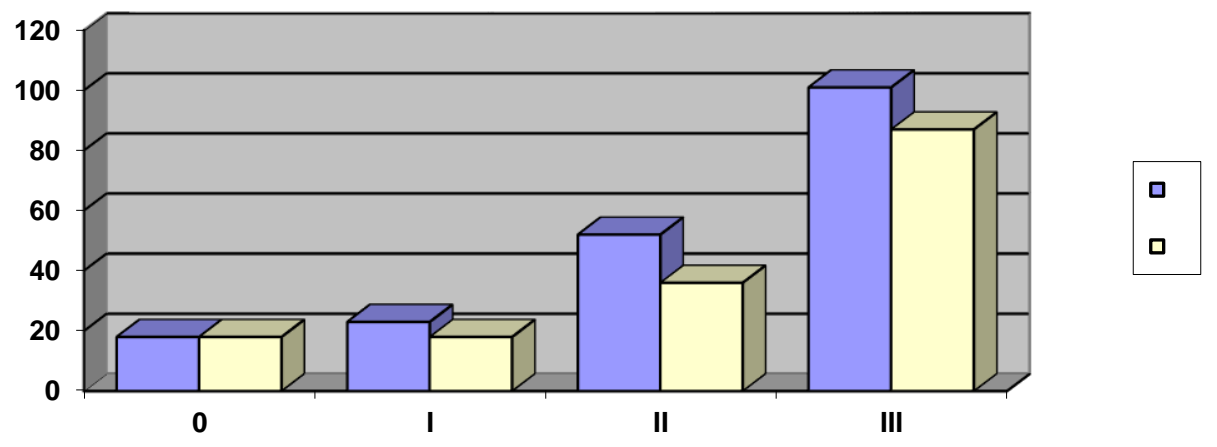

Gambar 1. Grafik Daya Pertumbuhan Ikan Mas Berdasarkan Jumlah Ekor per Kilogram Bobot.

Selain perhitungan jumlah ekor dalam setiap kilogram dan berat rata-rata setiap ekor ikan dihitung pula jumlah kematian ikan selama pemeliharaan sampai akhir pemeliharaan ikan pada petak pemeliharaan dengan pencakupan data kematian ikan selama pakan ditambah additive GH sebanyak 59 ekor sedangkan pada petakan pemeliharaan tanpa penambahan addtive GH sebanyak 88 ekor. Data jumlah kematian tersebut menunjukan bahwa dengan lebih sedikit nya jumlah ikan yang mati pada perlakuan penambahan additive Gh pada pakan tidak menimbulkan dampak negatip yang dapat menimbulkan kematian. Dari ketiga jenis data yang dipaparkan di atas menunjukan bahwa penggunaan additive GH pada pakan ikan yang diberikan pada ikan mas ditinjau dari sisi teknis tersebut memberikan dampak positip berupa laju pertumbuhan yang lebih baik tanpa efek samping yang negatip berupa kematian.

Ditinjau dari sisi ekonomi dengan perhitungan analisa usaha sederhana dapat ditampilkan dalam tabel 2. 
Tabel 2. Analisa Usaha Pembesaran Ikan Mas Dalam KJA

\begin{tabular}{|l|c|c|c|c|}
\hline \multirow{2}{*}{ Uraian } & \multirow{2}{*}{ Vol } & Harga Satuan & \multicolumn{2}{c|}{ Jumlah } \\
\cline { 4 - 5 } & & & & B \\
\hline Biaya & & 24.000 & 600.000 & 600.000 \\
- Benih & $25 \mathrm{Kg}$ & 5.300 & 2.120 .000 & 2.120 .000 \\
- Foman & $400 \mathrm{Kg}$ & 60.000 & 120.000 & - \\
\hline Jumlah & $2 \mathrm{btl}$ & & $\mathbf{2 . 8 4 0 . 0 0 0}$ & $\mathbf{2 . 7 2 0 . 0 0 0}$ \\
\hline Penjualan & & & & \\
A & & $\mathbf{1 3 . 2 0 0}$ & $\mathbf{3 . 6 9 6 . 0 0 0}$ & - \\
B & $\mathbf{2 8 0 ~ K g}$ & $\mathbf{1 3 . 2 0 0}$ & - & $\mathbf{2 . 9 4 6 . 4 0 0}$ \\
\hline Keuntungan & $\mathbf{2 2 7 ~ K g}$ & & $\mathbf{8 5 6 . 0 0 0}$ & $\mathbf{2 7 6 . 0 0 0}$ \\
R/C Ratio & & & $\mathbf{1 . 3}$ & $\mathbf{1 , 1}$ \\
B/C Ratio & & & $\mathbf{5 , 8 3}$ & \\
\hline
\end{tabular}

Ket: A Pemeliharaan dengan perlakuan

B Pemeliharaan tanpa perlakuan

Berdasarkan tampilan data pada tabel 2 dari sisi biaya terdapat selisih biaya sebesar Rp. 120.00,- sebagai akibat adanya perubahan teknologi berupa penambahan additive. Seyogyanya dari perubahan teknologi baru adalah adanya nilai tambah untu mengetahui sampai sejauh mana dampak positif dari penambahan additive $\mathrm{GH}$ pada pembesaran ikan mas dapat dilihat dari tiga aspek mulai dari keuntungan, R/C Ratio, dan B/C Ratio.

Dari tabel 2 dapat dilihat bahwa keuntungan yang diperoleh dari penggunaan additive GH mengalami peningkatan dengna selisih keuntungan sebesar Rp. 699.000,-.

Selanjutnya dari perhitungan R/C Ratio, seiring dengan adanya perubahan/perbedaan mulai peasukan menunjukan bahwa penggunaan additive $\mathrm{GH}$ memberikan dampak positif dengan ditandai angka R/C Ratio diperoleh sebesar 1,3 sedangkan yang tidak menggunakan additive R/C Rationya hanya 1,1.
Untuk lebih meyakinkan lagi bahwa penambahan additive GH memberikan dampak positif dilihat dari perhitungan B/C Ratio dimana angka yang dihasilkan adalah 5. 83. Angka ini menunjukan bahwa penambahan additive $\mathrm{GH}$ memberikan nilai tambah yang baik da banyak digunakan, karena angka yang layak sebagai nilai B/C Ratio untuk penggunaan teknologi baru harus lebih besar dari 1.

\section{KESIMULAN DAN SARAN}

Dari hasil percobaan penggunaan additive GH yang diberikan melalui makanan paa pembesaran ikan mas, dapat ditarik kesimpulan dan saran seperti di bawah ini.

\section{Kesimpulan :}

Penggunaan additive GH dengan cara dicampur dengan pakan (pelet) dalam pembesaran ikan mas dapat memberikan nilai tambah ekonomi berupa perubahan struktur 
pemasukan dan keuntungan yang disebabkan oleh terjadinya penambahan bobot akhir dari biomasa ikan yang dipanen.

\section{Saran :}

Masih dirasa perlu untuk dilakukan penelitian kembali untuk komoditas Ikan lain.

$>$ Para penbudidaya ikan mas disarankan untuk menggunakan makanan additive sebagai upaya menambah kelayakan usaha.

\section{DAFTAR PUSTAKA}

Agus Rochdianto. 1991. Budidaya Ikan di Jaring Terapung. PT. Penebar Swadaya, anggota IKAPI, Jakarta.

Nuraini I, dkk. 2005. Manajemen

Agribisnis. Sekolah Tinggi Penyuluhan

Perikanan, Bogor.
Teguh Trimulyantoro. 1987. Pedoman Budidaya Ikan Skala Kecil di dalam Waduk. Direktorat Jendral Perikanan bekerjasama dengan International Development Research Center, Jakarta.

Umar Husein. 2000. Studi Kelayakan Bisnis Manajemen, Metoda dan Kasus. Gramedia Pustaka Utama, Jakarta.

Zulkifli Jangkaru. 1996. Pembesaran Ikan Air Tawar di berbagai lingkungan pemeliharaan PT. Penebar Swadaya, anggota IKAPI Jakarta. 